\title{
Extraction Methods for Quantifying Iron, Calcium and Magnesium in a Historic Brickwork Produced During the Spanish Colonial Period in the Philippines
}

\author{
Jan-Michael C. Cayme,* and Aniano N. Asor, Jr. \\ Chemistry Department, College of Science, De La Salle University, 2401 Taft Avenue, Malate, Metro Manila
}

\begin{abstract}
This study demonstrates the feasibility of performing chemical analyses on heritage materials in the Philippines. Four extraction methods were evaluated based on the percentage of iron, calcium and magnesium in a clay brick sample obtained from an old Spanish colonial period church at Ilocos Norte. Aqua regia $\left(1: 3 \mathrm{HNO}_{3}: \mathrm{HCl}, \mathrm{v} / \mathrm{v}\right)$ solvent was used to extract these elements by conventional hot plate digestion. The extraction methods are: digesting the sample directly with aqua regia (M1), sample pre-digested with $\mathrm{NH}_{4} \mathrm{Cl}$ and ethyl alcohol prior to the actual digestion (M2) and soaking the sample with aqua regia for 24 hours (M3) and 48 hours (M4) before digestion. Atomic absorption spectroscopy (AAS) was employed to quantify the concentration of the intended elements. The percentage composition of iron ranges from 4.193 to $4.418 \%$, calcium from 0.123 to $0.203 \%$, and magnesium from 2.346 to $2.458 \%$, respectively. Energy-dispersive X-ray spectroscopy (EDX) analysis was done to support the data obtained from AAS. M1 was more effective in extracting calcium from the brick sample, while M2, M3 and M4 were useful for extracting iron and magnesium. Infrared spectroscopy (IR) provided a basic mineralogical composition of the sample, with peaks that were attributed to quartz, kaolinite, calcite, silicates and hematite.
\end{abstract}

Keywords: clay brick; aqua regia digestion method; atomic absorption spectroscopy; infrared spectroscopy; energy-dispersive X-ray spectroscopy; cultural heritage conservation

\section{INTRODUCTION}

Studying the chemical composition of historic brickwork is a vital factor in any proper restoration effort of heritage structures. This will ensure that the replacement brickwork is compatible in terms of type, color, texture and composition with the original material. The use of inappropriate materials for restoration work can lead to rapid deterioration of the heritage structure affecting its historical and aesthetic value (Lourenco et al., 2009). In the Philippines, contemporary brickwork is used rampantly as replacement bricks in some church renovations. Concrete blocks and powdered color additives are mixed to provide an artificial imitation of the original brickwork (Zialcita and Cruz-Angeles, 2007). These materials are selected without performing detailed chemical research and can 
cause problems on the old structure in the long run. Brick making techniques and source of brick materials during the Spanish colonial period may also vary depending on the local manufacturing process, region, environment and time span. Thus, a tailored approach on brick replacement based on chemical composition of the original brick material should be initiated in the Philippines.

Sampling of material is also an important issue for researches involving historical conservation. As a general rule, samples are removed only when necessary. A good sampling design has to be defined on the onset to ensure that only minimum amounts of heritage sample is taken from the site that corresponds to the type of analyses being planned (Hughes and Callebaut, 1999). Priority should also be given to nondestructive techniques such as $\mathrm{X}$-ray fluorescence (XRF), ultraviolet (UV) photography, proton-induced X-ray emission (PIXE), X-ray radiography and infrared thermography (Avdelidis and Moropoulou, 2004). These techniques, however, are effective for structural assessment, for physical evaluation of materials and for artworks (Uda et al., 2000). For the purpose of this study, which involves detailed bulk chemical analysis of the brick, removal of sample is an acceptable technique (Derrick et al., 1999; Figueiredo et al., 2001). Adequate sample for the analytical techniques used in this study required only picogram to milligram levels.

Bricks (ladrillos in Spanish) are composed of a mixture of clay (mainly montmorillonite and illite types), sand (quartz type) and water. It is subsequently moulded, pressed, dried for more than two weeks and finally fired in a brick kiln (borno in Spanish) at a temperature range of $800^{\circ} \mathrm{C}$ to $1,000^{\circ} \mathrm{C}$ depending on the raw materials used and the desired grade and purpose of the brick product (Navarro, 2007). Generally, the higher the temperature attained during firing, the stronger the brick formed (Cultrone et al., 2004). Crucial to the quality of the brick material produced is the property of the clay. The main chemical constituents of clays are silica and alumina, while typical minor constituents usually include iron, calcium (lime), magnesium (magnesia), potassium, sodium and titanium The percentage of each component would depend on the clay where it was collected (Fernandes et al., 2010). Since the amount of iron, calcium and magnesium can influence the brick's overall durability and strength, this study will focus on the quantification of these minor elements on a brick sample obtained from a Spanish colonial period church in the Ilocos Norte region. Specifically, iron is responsible for the characteristic reddish color of bricks. It is also a flux agent, important in making the brick durable, hard and strong (Somayaji, 2001). Calcium is another flux agent in the burning process which causes the silica from the sand to melt fusing the particle of the clay bricks together. Its amount is important because if present in excess, it can cause the brick product to melt and lose its shape (Gopi, 2010; Osabor et al., 2009). Magnesium also decreases the shrinkage of bricks and serves as another flux agent (Punmia, et al., 2005). The proportion of these three elements in the brick sample was quantified using atomic absorption spectroscopy (AAS) technique. Infrared spectroscopy (IR) technique was employed to have an idea of the general clay mineral composition of the sample (Schroeder, 2002). Energy-dispersive X-ray spectroscopy (EDX) technique was used to support the results acquired from AAS.

Since the brick is composed of clay, sample preparation techniques for rock and soil mineralogical analysis are generally applicable for this study (Mermut and Cano, 2001). Sample wet digestion is an essential preliminary method before quantification by AAS and aqua regia is effective in extracting the total recoverable metals in the clay brick sample (Chen and Ma, 2001). Conventional aqua regia digestion procedure involves digesting the brick samples with a 1:3 mixture of concentrated $\mathrm{HNO}_{3}$ and $\mathrm{HCl}$ on a hot plate, forming aqua regia: $3 \mathrm{HCl}_{(\mathrm{aq})}+\mathrm{HNO}_{3(\mathrm{aq})}$ $\rightarrow 2 \mathrm{H}_{2} \mathrm{O}_{(\mathrm{l})}+\mathrm{NOCl}_{(\mathrm{aq})}+\mathrm{Cl}_{2(\mathrm{~g})}$. The hotplate digestion method was used in this study. Variations in sample extraction methods prior to aqua regia digestion were investigated. These methods are as follows: (a) Method 1 (M1) is 
digesting the sample directly with aqua regia, (b) Method 2 (M2) is washing the sample with $\mathrm{NH}_{4} \mathrm{Cl}$ and ethyl alcohol through an ion exchange mechanism with $\mathrm{NH}_{4} \mathrm{Cl}$ (Mermut and Cano, 2001; Carroll, 1959), (c) Method 3 (M3) is soaking the sample in freshly prepared aqua regia for 24 hours before digestion, and lastly, (d) Method 4 (M4) is a variation of M3, by soaking the sample in freshly prepared aqua regia for 48 hours prior to digestion to enable the bonds to loosen initially.

\section{EXPERIMENTAL}

Description of Clay Brick Sample. The clay brick sample used to evaluate the different extraction methods for this study was acquired from a brick fragment measuring 17 $\mathrm{cm} \times 14.5 \mathrm{~cm} \times 9 \mathrm{~cm}$ situated on the facade of the Church of St. Joseph in Dingras, Ilocos Norte (Figure 1A) during a modern reconstruction effort of the parish in December 2011. The church is not listed in the National Cultural Church listings of the Philippines. The brick fragment (Figure 1B) has a dark reddish-brown outer surface and a light reddish-orange inner surface. Historical records placed the date of the church's construction in the late 1840's (Jose, et al., 2004). The reconstruction method preferred by the parish entails totally removing the original brick pieces one by one from the facade and eventually rebuilding it after retrofitting the structure with modern materials. The brick fragment was obtained during this removal process. From this fragment, loose broken pieces were carefully collected from the inner surface at a depth of approximately 1-2 inches relative to the outer surface. The rest of the fragment was returned afterwards. The collected broken pieces were eventually pulverized into powder $(34.7 \mathrm{~g})$ and served as the sample for digestion and for other spectroscopic analyses.

Analysis by Infrared Spectroscopy (IR). A small amount of the powdered brick sample (approximately 0.1 to $2.0 \%$ of the $\mathrm{KBr}$ amount) was mixed with $\mathrm{KBr}$ powder and ground together until the mixture became "pasty" and stuck to the mortar. The mixture was then pressed to form a thin and

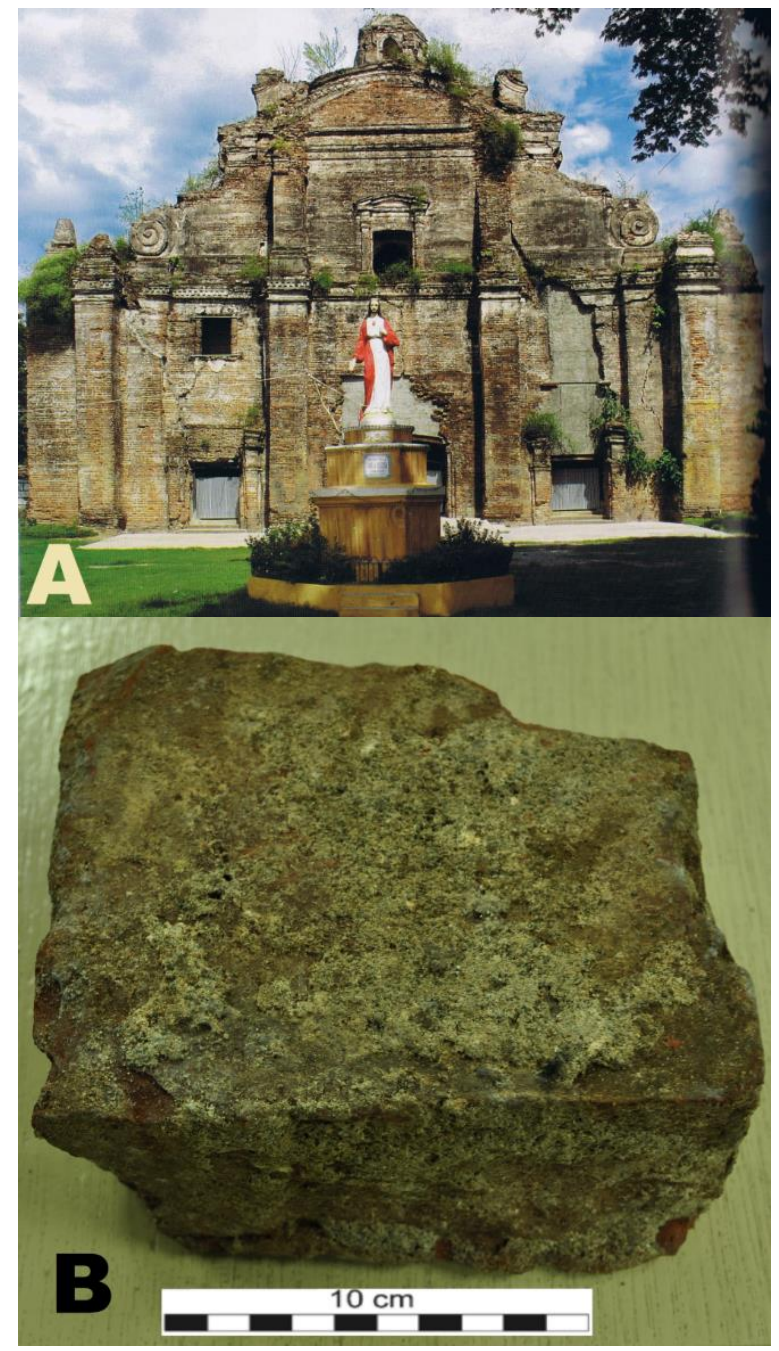

Figure 1: (A) The Ruined Church Facade at Dingras, Ilocos Norte before Reconstruction (Photo credit: Galende, 2007). As of date, this facade was remodelled using modern masonry and recycled old bricks. (B) The Historic Clay Brick Fragment Used in this Study where a Representative Sample for Analyses was Acquired.

transparent pellet. The infrared spectrum was recorded using a Thermo Scientific Nicolet 6700 FT-IR Spectrophotometer in the mid frequency region $\left(4000-400 \mathrm{~cm}^{-1}\right)$.

Digestion with Aqua Regia Solution. Four different sample preparation methods were employed prior to digestion with conventional aqua regia $\left(1: 3 \mathrm{HNO}_{3}: \mathrm{HCl}, \mathrm{v} / \mathrm{v}\right)$. The first method involves digesting brick samples directly without any pre-digestion step (M1), the second method involves washing the sample with $\mathrm{NH}_{4} \mathrm{Cl}$, serving as a pre-digestion step (M2), the third method, brick samples were soaked with freshly prepared aqua regia 
for 24 hours (M3), and the fourth method, brick samples were soaked for 48 hours (M4) before digestion. All samples were prepared in triplicates per extraction method.

Sample digested directly with aqua regia solution (M1). Three sample replicates of $0.5000 \mathrm{~g}$ powdered brick samples were placed in a 250 $\mathrm{mL}$ glass beaker covered with watch glass. It was digested in $40 \mathrm{~mL}$ of aqua regia for 3 hours on a hotplate at $110^{\circ} \mathrm{C}$ until near dryness. Each replicate was diluted with $20 \mathrm{~mL}$ of $2 \%$ $\mathrm{HNO}_{3}\left(\mathrm{v} / \mathrm{v}\right.$ with $\left.\mathrm{H}_{2} \mathrm{O}\right)$, placed in a centrifuge and decanted. The residue was discarded and the supernatant liquid was transferred to a 100 $\mathrm{mL}$ volumetric flask and diluted to the mark with distilled water (Chen and Ma, 2001).

Sample pre-digested with $1 \mathrm{M} \mathrm{NH} \mathrm{NH}_{4} \mathrm{Cl}$ prior to digestion with aqua regia solution (M2). Prior to aqua regia digestion, three replicate powdered brick samples weighing $0.5000 \mathrm{~g}$ each were washed with a solution of $1 \mathrm{M} \mathrm{NH} \mathrm{NH}_{4} \mathrm{Cl}$ three times followed by $50 \%$ ethanol $\left(\mathrm{v} / \mathrm{v} \mathrm{H}_{2} \mathrm{O}\right)$. Once the supernatant solution was determined free of chloride ions using $\mathrm{AgNO}_{3}$, the solution was centrifuged and decanted. Each sample residue was dried on an oven for 24 hours at $105^{\circ} \mathrm{C}$ (Mermut and Cano, 2001). Once dried, the procedure for aqua regia digestion was followed.

Samples soaked for 24 hour with aqua regia solution (M3). Three replicate samples weighing 0.5000 $\mathrm{g}$ each were soaked in $50 \mathrm{~mL}$ aqua regia solution at room temperature for 24 hours prior to digestion. After the initial reaction period, each sample was further digested continually with another $40 \mathrm{~mL}$ of aqua regia solution on a hotplate $\left(110^{\circ} \mathrm{C}\right)$ for 3 hours. After evaporation to near dryness, each sample was diluted with $20 \mathrm{~mL}$ of $2 \% \mathrm{HNO}_{3}$ (v/v with $\mathrm{H}_{2} \mathrm{O}$ ), and was centrifuged to separate the residue, then decanted. The supernatant liquid was placed in a $100 \mathrm{~mL}$ volumetric flask and diluted to the mark with distilled water (Chen and Ma, 2001).

Samples soaked for 48 hours with aqua regia solution (M4). The same procedure for 24 hours soaking period was followed (M3), with the exception that another triplicate samples were soaked in freshly prepared aqua regia for 48 hours prior to digestion.

Analysis by Atomic Absorption Spectroscopy (AAS). External standard method was employed to determine the concentrations of iron, calcium and magnesium in the clay brick sample. Calibration curves were constructed from a series of standard solutions of known analyte concentrations, prepared from a 1000 ppm stock solution. The blank solution used throughout the experiment was $2 \% \mathrm{HNO}_{3}$ ( $\mathrm{v} / \mathrm{v} \mathrm{H}_{2} \mathrm{O}$ ). Since the calcium and magnesium atoms are prone to chemical interferences, a chemical suppressant composed of $5 \% \mathrm{w} / \mathrm{v}$ $\mathrm{Sr}\left(\mathrm{NO}_{3}\right)_{2}$ was added to each standard and sample. Each absorbance measurement was performed in triplicate. The absorbance was recorded in a Shimadzu AA-6300 Atomic Absorption Spectrophotometer with an airacetylene gas mixture. Absorbance measurements was taken at $248.3 \mathrm{~nm}$ for iron, $422.7 \mathrm{~nm}$ for calcium and $285.2 \mathrm{~nm}$ for magnesium, respectively, using hallow cathode lamps as radiation source.

Standardization of Iron. A series of standard solutions ranging from $2 \mathrm{ppm}$ to $10 \mathrm{ppm}(2,4$, $6,8,10 \mathrm{ppm})$ was prepared from a commercially available $1000 \mathrm{ppm}$ iron atomic spectroscopy standard concentrate (Fluka brand, analytical standard grade) and diluted to the mark with $2 \% \mathrm{HNO}_{3}\left(\mathrm{v} / \mathrm{v} \mathrm{H}_{2} \mathrm{O}\right)$ in a $100 \mathrm{~mL}$ volumetric flask. A $3 \mathrm{~mL}$ aliquot of the digested brick sample representing each preparation method was pipetted into a 100 $\mathrm{mL}$ volumetric flask and diluted with $2 \%$ $\mathrm{HNO}_{3} \quad\left(\mathrm{v} / \mathrm{v} \quad \mathrm{H}_{2} \mathrm{O}\right)$. This served as the unknown sample.

Standardization of Calcium. Standard solutions were prepared from a commercially available 1000 ppm calcium atomic spectroscopy standard concentrate (Fluka brand, analytical standard grade) with concentrations ranging from $0.1 \mathrm{ppm}$ to $2 \mathrm{ppm}(0.1,0.3,0.5,1,1.3$, 1.5, $2 \mathrm{ppm})$. A $2.5 \mathrm{~mL} \mathrm{Sr}\left(\mathrm{NO}_{3}\right)_{2}$ solution was added into each standard solution and diluted to the mark with $2 \% \mathrm{HNO}_{3}\left(\mathrm{v} / \mathrm{v} \mathrm{H}_{2} \mathrm{O}\right)$ in a 50 $\mathrm{mL}$ volumetric flask. For the unknown 
sample, a $15 \mathrm{~mL}$ aliquot of each digested brick sample was added with $30 \mathrm{~mL} \operatorname{Sr}\left(\mathrm{NO}_{3}\right)_{2}$ and diluted to the mark with $2 \% \mathrm{HNO}_{3}(\mathrm{v} / \mathrm{v}$ $\left.\mathrm{H}_{2} \mathrm{O}\right)$ in a $100 \mathrm{~mL}$ volumetric flask.

Standardization of Magnesium. Standard solutions ranging from $0.3 \mathrm{ppm}$ to $1 \mathrm{ppm}(0.3,0.5,0.8$ and $1 \mathrm{ppm})$ were prepared from a commercially available 1000 ppm magnesium atomic spectroscopy standard concentrate (Fluka brand, analytical standard grade) and subsequently added with $2.5 \mathrm{~mL} \mathrm{Sr}\left(\mathrm{NO}_{3}\right)_{2}$. The resulting mixture was diluted to the mark in a $50 \mathrm{~mL}$ volumetric flask using $2 \% \mathrm{HNO}_{3}$ (v/v $\mathrm{H}_{2} \mathrm{O}$ ). A $1 \mathrm{~mL}$ aliquot was taken from the unknown brick sample solution prepared for calcium, for it to fall within the standard concentration range, and was diluted to the mark in a $50 \mathrm{~mL}$ volumetric flask.

\section{Analysis by Energy-dispersive $X$-ray} Spectroscopy $(\boldsymbol{E D X})$. Sample for analysis was prepared by dispersing a small amount of dry, powdered brick sample on double-sided conductive adhesive tape attached on an aluminium stub. It was then coated with gold for 15 seconds. The EDX spectrum was recorded using the SEM/EDX JEOL JSM5310 scanning microscope combined with Oxford Link Isis in the spot-profile mode by focusing the electron beam onto specific regions of the sample. System resolution during elemental analysis was taken at $60 \mathrm{eV}$.

\section{RESULTS AND DISCUSSION}

Basic Mineralogical Composition using Infrared Spectroscopy (IR). Examining the mid-IR region (4000 to $400 \mathrm{~cm}^{-1}$ ) of the spectrum provided information on the constituent of clay minerals found on the brick sample. Generally, the spectral range from 3400 to $3750 \mathrm{~cm}^{-1}$ was assigned to $\mathrm{OH}$ stretching modes, which is common to most clay minerals. Stretching modes for $\mathrm{Si}-\mathrm{O}$ and Al-O at 700 to $1200 \mathrm{~cm}^{-1}$, while for bending modes, 150 to $600 \mathrm{~cm}^{-1}$. Metal-OH bending modes were seen from 600 to $950 \mathrm{~cm}^{-1}$ (Schroeder, 2002).

The FTIR spectrum of the brick sample (Figure 2) has a broad band centered at
$3407.72 \mathrm{~cm}^{-1}$ which corresponds to the $\mathrm{OH}$ stretching vibration of the absorbed water molecule. This was complimented by the band centered at $1715.36 \mathrm{~cm}^{-1}$ assigned to the bending $\mathrm{H}-\mathrm{O}-\mathrm{H}$ vibration of water as a result of its exposure from the atmosphere (Sathya, et al., 2012). The intense absorption band at $1091.74 \mathrm{~cm}^{-1}$ was attributed to the stretching vibration of Si-O of the clay's tetrahedral layer, probably in the quartz phase (Senvaitiene, et al., 2007). It may also indicate a white clay origin of kaolinite (Ghosh, 1978). The presence of quartz was supported by the sharp Si-O vibration at $780.94 \mathrm{~cm}^{-1}$. A weak absorption band at $1457.22 \mathrm{~cm}^{-1}$ was characteristic of the $\mathrm{C}-\mathrm{O}$ antisymmetric stretching vibration $\left(\mathrm{V}_{3}\right)$ of calcite in the brick sample (Sathya, et al., 2012). Calcite can also be identified from the Si-OH stretching at $2344.64 \mathrm{~cm}^{-1}$ (Nwosu, et al., 2013). Metaloxygen vibrations were evident from the absorption peaks at $594.28 \mathrm{~cm}^{-1}$, assigned to the mineral magnetite $\left(\mathrm{Fe}^{2+}\right.$ or $\left.\mathrm{Fe}^{3+}{ }_{2} \mathrm{O}_{4}\right)$ and at $534.14 \mathrm{~cm}^{-1}$ for hematite $\left(\mathrm{Fe}_{2} \mathrm{O}_{3}\right)$. Bending vibrations for the $\mathrm{Si}-\mathrm{O}-\mathrm{Si}$ were indicated on the peaks at $466.76 \mathrm{~cm}^{-1}$ and at $646.42 \mathrm{~cm}^{-1}$ for silicates.

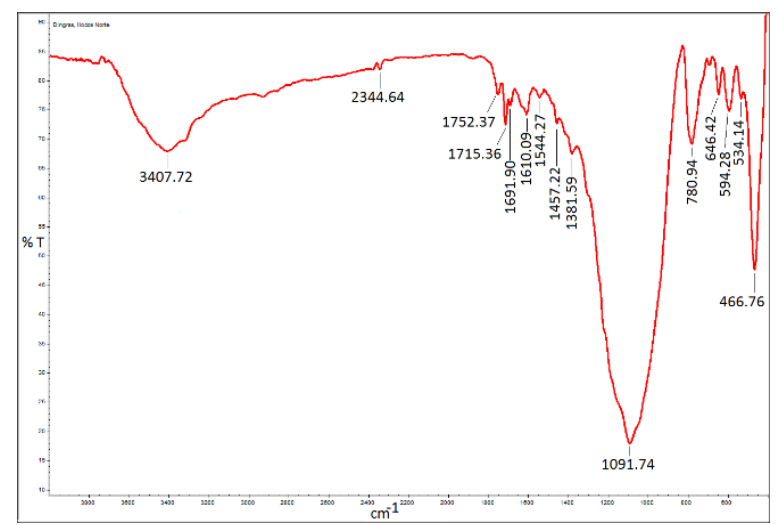

Figure 2: Spectrum of the Mid-Infrared Region $\left(4000-400 \mathrm{~cm}^{-1}\right)$ of the Brick Sample.

Sample Digestion with Aqua Regia. The efficiency of the different extraction methods was evaluated by the percentage composition of iron $\left(\mathrm{Fe}^{2+},{ }^{3+}\right)$, calcium $\left(\mathrm{Ca}^{2+}\right)$ and magnesium $\left(\mathrm{Mg}^{2+}\right)$ in the brick sample using AAS. Based on the IR spectrum, these elements were originally present as clay mineral components of the brick sample. Clay minerals are generally arranged into layers 
composed of silica tetrahedron and alumina octahedron sheets together in different ratios (1:1 or $2: 1$, silica: alumina). Iron $\left(\mathrm{Fe}^{2+}, \mathrm{Fe}^{3+}\right)$ and magnesium $\left(\mathrm{Mg}^{2+}\right)$ can substitute for aluminium $\left(\mathrm{Al}^{3+}\right)$ in the alumina octahedron layer, creating a net negative charge on the clay structure (Velda, 1992; Torraca, 1988) and will attract exchangeable ions (i.e. $\mathrm{Ca}^{2+}$ ) that can collect in between the interlayer. These arrangements would form the basis for the different extraction techniques employed in this study. Soaking the samples in aqua regia undisturbed for 24 hours and 48 hours, respectively (M3 and M4) before digestion would ensure sufficient dissolution of iron and magnesium held within the octahedral layer. Exchange of $\mathrm{Ca}^{2+}$ with $\mathrm{NH}_{4} \mathrm{Cl}$ and ethanol (M2) can facilitate its release from the interlayer, as well as some fragments of $\mathrm{Fe}^{2+, 3+}$ and $\mathrm{Mg}^{2+}$ that may have deposited within the interlayer. These pre-treatment methods were compared to the sample that was digested immediately (M1) after adding freshly prepared aqua regia in a hot plate.

Percentage of Iron in the Brick Sample. Significant amount of iron in the brick sample was supported by the IR spectrum having absorption peaks for the mineral magnetite and hematite. Iron is a natural colorant of clay bricks which gives the characteristic redorange and reddish-brown color. It is usually present in small quantities. Various studies on old clay bricks using $\mathrm{x}$-ray techniques done in other countries, report the percentage of iron from $3.0 \%$ to about $14.0 \%$. Specifically, old clay bricks obtained from different historical structures in Portugal dating from the $12^{\text {th }}$ to the $19^{\text {th }}$ century, report the iron content to be about 4.1 to $11.4 \%$ (Fernandes, et al., 2010), while burnt clay bricks from India dating from the $17^{\text {th }}$ to $18^{\text {th }}$ century, range from $3.2 \%$ to 13.6\% (Rai and Dhanapal, 2013). Since brickmaking techniques and the proportion of brick raw materials are more or less similar during these time periods, it is expected that the sample would be within this percentage range.

Analysis by AAS involves preparing iron standard solutions from a stock solution of known concentration. To prevent deviations from linearity (Beer's Law), an ideal concentration range was prepared from 2 to $10 \mathrm{ppm}$ and the digested brick sample was diluted to fit within this range. The equation of the line for the three set of calibration curves are as follows; for Trial 1: $\mathrm{y}=$ $0.004810 \mathrm{x}-0.0007000(\mathrm{r}=0.9983)$, Trial 2: $\mathrm{y}$ $=0.004715 \mathrm{x}+0.0002100(\mathrm{r}=0.9975)$, and Trial 3: $\mathrm{y}=0.004700 \mathrm{x}+0.001960(\mathrm{r}=$ 0.9936), signifying that the prepared standards are within the regression line. Table 1 lists the percentage of iron obtained from the different methods which ranges from 4.193 to $4.418 \%$. A clay brick that was manufactured and fired well should have iron percentage values not greater than $7.0 \%$ (Punmia, et al., 2005). This indicates that the brick sample was made within acceptable standards. Data shows that there is no drastic difference $(<0.25 \%$ iron) among the four methods (Figure 2), though M2, M3, and M4 yielded higher percentage of iron compared to M1. Soaking the brick samples for 24 hours (M3) and 48 hours (M4) hours in aqua regia before digestion seems to be the best method in extracting iron. This implies that soaking the sample within a given time period will facilitate the initial breakdown of bonds in the outer surface layer of the clay matrix, effectively leaching the iron in the solution. Ion exchange by $\mathrm{NH}_{4}^{+}$(M2) is almost comparable with that of M4. Ammonium ion doesn't exchange efficiently with iron due to its size (Bohn et al., 2001), but readily replaces smaller ions in the interlayer. This exchange can disrupt the charge balance of the entire clay structure and weaken the bonds, thus making the added aqua regia during the digestion stage more effective.

Comparing the standard deviations (Figure 3) of the different methods, the sample soaked for 48 hours (M4) has the lowest standard deviation value of 0.032 signifying that the values obtained were more clustered around the mean. AAS analysis was done concurrently by the same analyst throughout the experiment. Precision was dictated by the nature of the sample itself because the iron concentration is not evenly distributed in the original brick sample and deviations can occur. 
Table 1: Summary of the Atomic Absorption Spectroscopy (AAS) Data for Iron Content.

\begin{tabular}{|c|c|c|c|c|c|c|}
\hline $\begin{array}{l}\text { Sample } \\
\text { Code }\end{array}$ & $\begin{array}{c}\text { Mass of brick } \\
\text { sample (g) }\end{array}$ & $\begin{array}{l}\text { Trial 1 } \\
(\% \mathrm{Fe}) \\
\end{array}$ & $\begin{array}{l}\text { Trial } 2 \\
(\% \mathrm{Fe}) \\
\end{array}$ & $\begin{array}{l}\text { Trial } 3 \\
(\% \mathrm{Fe}) \\
\end{array}$ & $\begin{array}{c}\text { Average } \\
(\% \mathrm{Fe})\end{array}$ & $\begin{array}{c}\text { Mean and } \\
\text { (Std. Deviation) }\end{array}$ \\
\hline M1-01 & 0.5013 & 4.617 & 3.722 & 4.377 & 4.239 & \multirow{3}{*}{$4.193(0.125)$} \\
\hline M1-02 & 0.5017 & 3.964 & 4.226 & 3.964 & 4.051 & \\
\hline M1-03 & 0.5018 & 4.378 & 4.197 & 4.288 & 4.288 & \\
\hline M2-01 & 0.5014 & 4.450 & 4.214 & 3.910 & 4.192 & \multirow{3}{*}{$4.334(0.124)$} \\
\hline M2-02 & 0.5026 & 5.184 & 3.811 & 4.239 & 4.411 & \\
\hline M2-03 & 0.5015 & 4.823 & 3.974 & 4.404 & 4.400 & \\
\hline M3-01 & 0.5025 & 4.399 & 3.994 & 4.254 & 4.216 & \multirow{3}{*}{$4.418(0.215)$} \\
\hline M3-02 & 0.5020 & 4.956 & 3.942 & 4.286 & 4.395 & \\
\hline M3-03 & 0.5025 & 4.992 & 4.641 & 4.296 & 4.643 & \\
\hline M4-01 & 0.5026 & 5.047 & 3.839 & 4.225 & 4.370 & \multirow{3}{*}{$4.340(0.032)$} \\
\hline M4-02 & 0.5008 & 5.078 & 3.909 & 4.042 & 4.343 & \\
\hline M4-03 & 0.5015 & 4.864 & 3.847 & 4.206 & 4.306 & \\
\hline
\end{tabular}

M1-digested directly, M2-washed with $\mathrm{NH}_{4} \mathrm{Cl}$, M3-soaked for 24 hours, M4-soaked for 48 hours

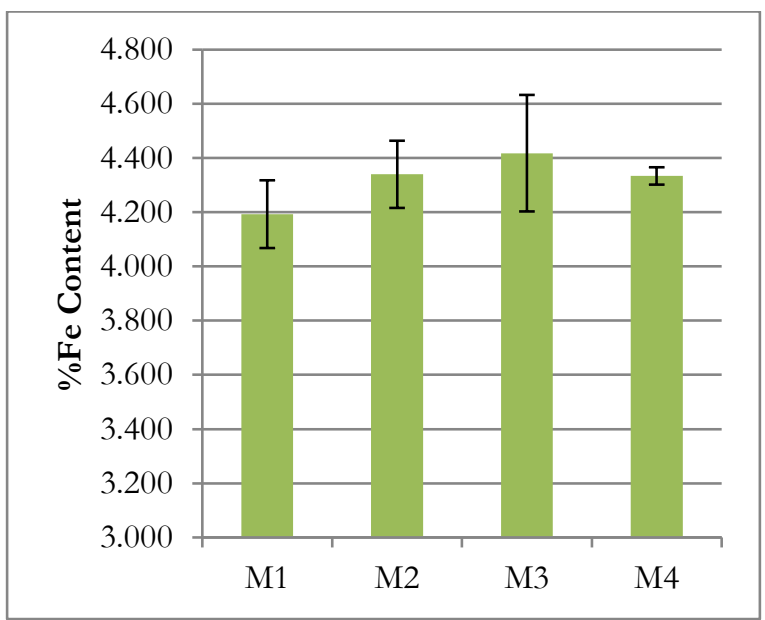

Figure 3: Distribution of Iron in the Brick Sample with Standard Deviation.

Percentage of Calcium in the Brick Sample. A calibration curve was prepared from a calcium standard solution, diluted within the concentration range of 0.1 to 2 ppm. At this range, the absorption of calcium in AAS is linear and obeys Beer's Law. Three sets of calibration curves were prepared and the equation of each line are as follows; Trial 1: $\mathrm{y}=0.1386 \mathrm{x}-0.003318(\mathrm{r}=0.9945)$, Trial 2: $\mathrm{y}=0.1486 \mathrm{x}-0.003581(\mathrm{r}=0.9939)$ and for Trial 3: $\mathrm{y}=0.1513 \mathrm{x}-0.002451(\mathrm{r}=$ 0.9859). The percentage of calcium obtained from the four methods ranges from 0.123 to $0.203 \%$, as shown in Table 2. The low percentage of calcium may indicate that the sample preparation was not contaminated with lime mortar normally attached to the brick's surface (Rai and Dhanapal, 2013). Furthermore, a well manufactured clay brick should have a calcium content not exceeding $5.0 \%$ (Gopi, 2010), signifying that the brick sample in this study was within standards.

Among the four digestion methods, M1 yielded a higher percentage of calcium, $0.203 \%$, compared to M2, M3 and M4. The standard deviation values of each method indicate that the experiment was conducted uniformly. Since calcium can be readily displaced by $\mathrm{NH}_{4}{ }^{+}$in the interlayer (Buehrer, 1952; Carroll, 1959) as in the case of M2, there is a possibility that it may have been removed during the washing process, explaining its low calcium composition $(0.127 \%)$. The supernatant was discarded every washing step and it may contain calcium that exchanged with $\mathrm{NH}_{4}^{+}$. Soaking the sample with aqua regia solution for 24 hours (M3) and for 48 hours (M4) prior to heating on a hot plate was moderately effective in releasing calcium in the sample matrix. In the absence of heat, the permeability of aqua regia in the interlayer, where calcium is normally embedded, was decreased. Expanding or swelling capacity of the interlayer to release the calcium is greatly influenced by the type of clay material that constitutes the sample (Sposito et al., 1999). 
Table 2: Summary of the Atomic Absorption Spectroscopy (AAS) Data for Calcium Content.

\begin{tabular}{|c|c|c|c|c|c|c|}
\hline $\begin{array}{l}\text { Sample } \\
\text { Code }\end{array}$ & $\begin{array}{c}\text { Mass of brick } \\
\text { sample (g) }\end{array}$ & $\begin{array}{l}\text { Trial 1 } \\
(\% \mathrm{Ca})\end{array}$ & $\begin{array}{l}\text { Trial } 2 \\
(\% \mathrm{Ca})\end{array}$ & $\begin{array}{l}\text { Trial 3 } \\
(\% \mathrm{Ca})\end{array}$ & $\begin{array}{c}\text { Average } \\
(\% \mathrm{Ca})\end{array}$ & $\begin{array}{c}\text { Mean and } \\
\text { (Std. Deviation) }\end{array}$ \\
\hline M1-01 & 0.5013 & 0.174 & 0.168 & 0.176 & 0.173 & \multirow{3}{*}{$0.203(0.026)$} \\
\hline M1-02 & 0.5017 & 0.222 & 0.222 & 0.228 & 0.224 & \\
\hline M1-03 & 0.5018 & 0.214 & 0.208 & 0.211 & 0.211 & \\
\hline M2-01 & 0.5014 & 0.150 & 0.148 & 0.153 & 0.150 & \multirow{3}{*}{$0.127(0.040)$} \\
\hline M2-02 & 0.5026 & 0.085 & 0.079 & 0.079 & 0.081 & \\
\hline M2-03 & 0.5015 & 0.155 & 0.149 & 0.146 & 0.150 & \\
\hline M3-01 & 0.5025 & 0.168 & 0.163 & 0.167 & 0.166 & \multirow{3}{*}{$0.165(0.066)$} \\
\hline M3-02 & 0.5020 & 0.102 & 0.101 & 0.094 & 0.099 & \\
\hline M3-03 & 0.5025 & 0.235 & 0.230 & 0.230 & 0.231 & \\
\hline M4-01 & 0.5026 & 0.130 & 0.119 & 0.118 & 0.123 & \multirow{3}{*}{$0.123(0.021)$} \\
\hline M4-02 & 0.5008 & 0.105 & 0.104 & 0.097 & 0.102 & \\
\hline M4-03 & 0.5015 & 0.155 & 0.142 & 0.137 & 0.145 & \\
\hline
\end{tabular}

M1-digested directly, M2-washed with $\mathrm{NH}_{4} \mathrm{Cl}$, M3-soaked for 24 hours, M4-soaked for 48 hours

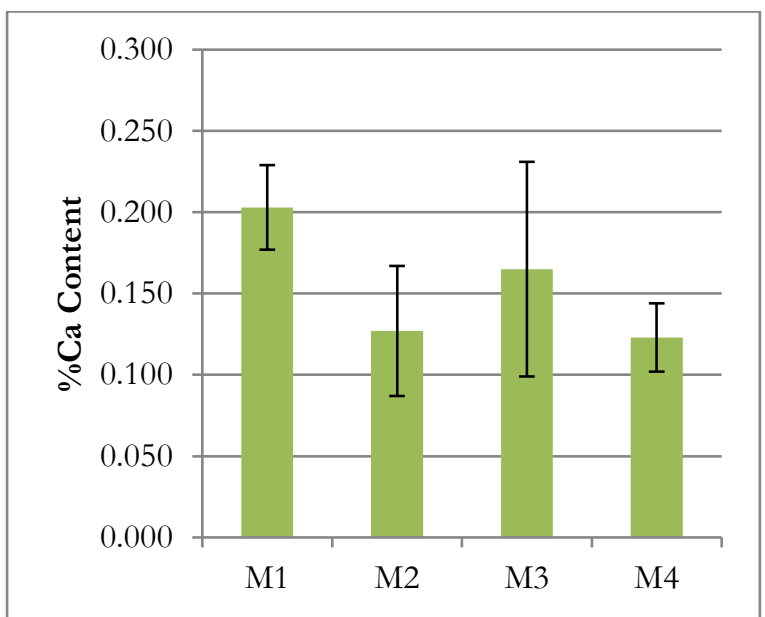

Figure 4: Distribution of Calcium in the Brick Sample with Standard Deviation.

Percentage of Magnesium in the Brick Sample. To prevent deviations from Beer's Law, the calibration curve for magnesium was prepared within the concentration range of 0.3 to $1 \mathrm{ppm}$. The equation of the line derived from this concentration range are as follows; for Trial 1: $\mathrm{y}=1.222 \mathrm{x}-0.2134(\mathrm{r}=0.9997)$, for Trail 2: $\mathrm{y}=1.254 \mathrm{x}-0.2393(\mathrm{r}=0.9989)$ and for Trial 3: $y=1.244 \times-0.2275(r=0.9976)$. The prepared calibration standards were linear within the set of concentration range.

Upon dilution to fit within the given standard range and absorbance measurements from AAS was obtained, the percentage of magnesium computed for the four different extraction methods range from $2.346 \%$ to $2.458 \%$ (Table 3 and Figure 5). The difference between each value is quite small, approximately $<0.115 \%$, indicating that either method was effective in extracting magnesium from the brick sample. Sample preparation and AAS analysis was done at the same time by the same analyst, reducing personal and systematic errors. Based on literature, the magnesium content for a good quality old brick should be $<1 \%$ and the values obtained from this study are within this range (Punmia et al., 2005).

However, since magnesium can also be found in the clay's interlayer, it is capable of ion exchange with $\mathrm{NH}_{4}^{+}$(Buehrer, 1952; Carroll, 1959) and may have been removed during the washing process, thus, compared to the other extraction methods, this resulted to the relatively lower percentage value of M2 $(2.346 \%)$. From the extraction procedure of $\mathrm{M} 2$, the brick sample residue was washed three times with $\mathrm{NH}_{4} \mathrm{Cl}$ and the supernatant liquid was discarded every step. It is possible that the supernatant liquid might contain magnesium. Magnesium is also less replaceable (Carroll, 1959) than calcium due to its smaller size which explains why more calcium was exchanged by $\mathrm{NH}_{4}{ }^{+}$in solution. 
Table 3: Summary of the Atomic Absorption Spectroscopy (AAS) Data for Magnesium Content.

\begin{tabular}{|c|c|c|c|c|c|c|}
\hline $\begin{array}{l}\text { Sample } \\
\text { Code }\end{array}$ & $\begin{array}{c}\text { Mass of brick } \\
\text { sample (g) }\end{array}$ & $\begin{array}{c}\text { Trial 1 } \\
(\% \mathrm{Mg}) \\
\end{array}$ & $\begin{array}{c}\text { Trial } 2 \\
(\% \mathrm{Mg}) \\
\end{array}$ & $\begin{array}{l}\text { Trial 3 } \\
(\% \mathrm{Mg}) \\
\end{array}$ & $\begin{array}{l}\text { Average } \\
(\% \mathrm{Mg})\end{array}$ & $\begin{array}{c}\text { Mean and } \\
\text { (Std. Deviation) }\end{array}$ \\
\hline M1-01 & 0.5013 & 2.333 & 2.406 & 2.348 & 2.362 & \multirow{3}{*}{$2.440(0.112)$} \\
\hline M1-02 & 0.5017 & 2.349 & 2.429 & 2.392 & 2.390 & \\
\hline M1-03 & 0.5018 & 2.544 & 2.618 & 2.546 & 2.569 & \\
\hline M2-01 & 0.5014 & 2.309 & 2.416 & 2.361 & 2.362 & \multirow{3}{*}{$2.346(0.016)$} \\
\hline M2-02 & 0.5026 & 2.280 & 2.366 & 2.345 & 2.330 & \\
\hline M2-03 & 0.5015 & 2.292 & 2.383 & 2.361 & 2.345 & \\
\hline M3-01 & 0.5025 & 2.481 & 2.579 & 2.528 & 2.529 & \multirow{3}{*}{$2.458(0.067)$} \\
\hline M3-02 & 0.5020 & 2.404 & 2.490 & 2.455 & 2.449 & \\
\hline M3-03 & 0.5025 & 2.347 & 2.449 & 2.393 & 2.397 & \\
\hline M4-01 & 0.5026 & 2.407 & 2.516 & 2.496 & 2.473 & \multirow{3}{*}{$2.391(0.085)$} \\
\hline M4-02 & 0.5008 & 2.235 & 2.357 & 2.320 & 2.304 & \\
\hline M4-03 & 0.5015 & 2.327 & 2.471 & 2.388 & 2.395 & \\
\hline
\end{tabular}

M1-digested directly, M2-washed with $\mathrm{NH}_{4} \mathrm{Cl}$, M3-soaked for 24 hours, M4-soaked for 48 hours

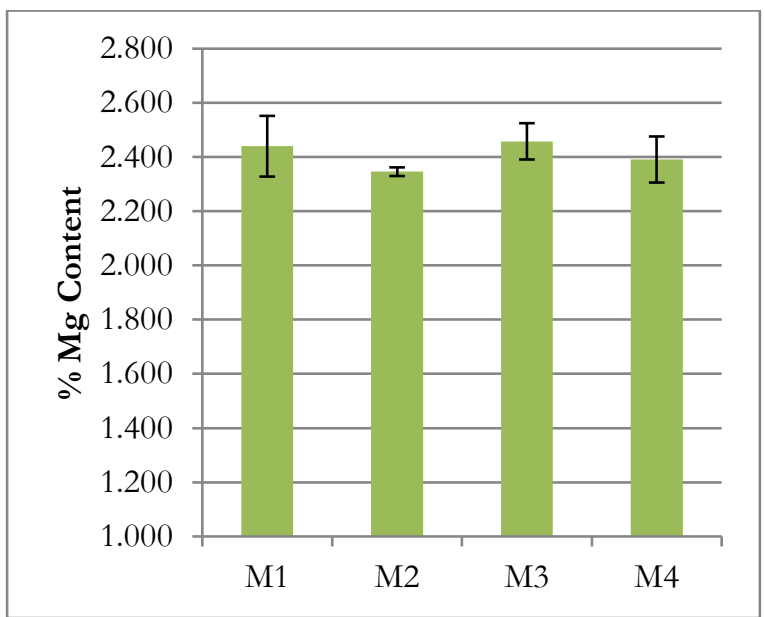

Figure 5: Distribution of Magnesium in the Brick Sample with Standard Deviation.

Elemental Analysis using EnergyDispersive $X$-Ray Spectroscopy (EDX). Based on the AAS and EDX data (Table 4), the distribution of the amount of iron, calcium and magnesium in the brick sample showed good agreement. The difference between the percentage values of iron obtained from AAS $(4.418 \%)$ with that of $\operatorname{EDX}(3.18 \%)$ is quite small, indicating that iron is distributed evenly in the brick sample matrix. For calcium and magnesium, the percentage difference between the two techniques was greater than $50 \%$. Since EDX is a spot analysis technique, it is possible that the distribution of calcium and magnesium in the scanned area was not uniform compared to AAS where the bulk sample was considered for analysis.
Table 4: Comparison of AAS and EDX Data for Iron, Calcium and Magnesium.

\begin{tabular}{cccc}
\hline Instrument & $\mathrm{Fe}$ & $\mathrm{Ca}$ & $\mathrm{Mg}$ \\
\hline EDX & $3.18 \%$ & $0.57 \%$ & $1.11 \%$ \\
\hline AAS $^{*}$ & $4.418 \%$ & $0.203 \%$ & $2.458 \%$ \\
\hline
\end{tabular}

*based on the extraction method that yielded the highest amount of $\mathrm{Fe}, \mathrm{Ca}$ and $\mathrm{Mg}$

\section{CONCLUSION}

The proposed digestion methods yielded quantifiable amounts of iron, calcium and magnesium content in the old clay brick sample using AAS. These results were supported by EDX data. For elements that are attached to the layer structure of clay, i.e. iron and magnesium, M2, M3 and M4 was more appropriate for extraction and yielded higher percentage amount compared to M1. However, exchangeable cations like calcium which can be found in the interlayer of the clay structure, the most effective method is M1. The IR data also verified that the brick sample was of clay and sand origin. This study was essential in identifying the specific methods to be employed to maximize the extraction of these elements and to aid in finding the most appropriate replacement brick material for conservation work. 


\section{ACKNOWLEDGEMENT}

The authors would like to express their sincere gratitude to the Municipality of Dingras, Ilocos Norte and most especially to the Parish of St. Joseph for the old clay brick sample used in this study. The generous support of the Chemistry Department of the De La Salle University, Manila, is highly appreciated. This study is not possible without the helpful insights and assistance of the following persons: Dr. Marissa Noel, Mr. Michael Ajero, Mr. Irving Chiong, Dr. Maria Carmen Tan, Mr. Mamerto Quizon, Dr. Marietta Ilao, Dr. Lourdes Guidote and Mr. Reynaldo Coria.

\section{DEDICATION}

This study would bopefully inspire Filipinos to appreciate, respect and admire their unique architectural built heritage; to show remorse to what has been lost forever and to take care of what remains.

\section{REFERENCES}

Avdelidis NP, Moropoulou A. Applications of Infrared Thermography for the Investigation of Historic Structures. J Cult Herit. 2004; 5:119-127.

Bohn HL, McNeal BL, O'Connor GA. Soil Chemistry. $3^{\text {rd }}$ ed. John Wiley \& Sons, Inc.; 2001.

Buehrer TF. Part IV: Clay Technology in Soil Science. Role of Chemical Properties of Clays in Soil Science. Clays Clay Miner. 1952; 1(1):177-187.

Carroll D. Ion Exchange in Clays and Other Minerals. Geol Soc Am Bull. 1959 June; 70(6):749-779.

Chandigarh T. Civil Engineering Materials. $1^{\text {st }}$ ed. McGraw Hill Higher Education; 2005.

Chen M, Ma LQ. Comparison of Three Aqua Regia Digestion Methods for Twenty Florida Soils. Soil Sci Soc Am J. 2001; 65:491-499.
Cultrone G, Sebastián E, Elert K, De La Torre MJ, Cazalla O, Rodriguez-Navarro C. Influence of mineralogy and firing temperature on the porosity of bricks. J Eur Ceram Soc. 2004; 24:547-564.

Derrick MR, Stulik D, Landry JM. Infrared Spectroscopy in Conservation Science: Scientific Tools for Conservation. Los Angeles: The Getty Conservation Institute; 1999.

Fernandes F, Lourenco P, Castro F. Ancient Clay Bricks: Manufacture and Properties. In: Bostenaru Dan M, Poikryl R, Torok A. Materials, Technologies and Practice in Historic Heritage Structures. Netherlands: Springer; 2010. p. 29-48.

Figueiredo MO, Veiga JP, Silva TP. Materials and Reconstruction Techniques at the Aqueduct of Carthage Since the Roman Period. In: Lourenco PB, Roca P, editors. Historical Constructions. Guimaraes; 2001. p. 391-400.

Galende, OSA PG. Philippine Church Facades. Vibal Publishing House Inc. (Filipiniana.net) and San Agustin Museum; 2007.

Gopi S. Basic Civil Engineering. Pearson Education India; 2010.

Ghosh SN. Infra-red Spectra of Some Selected Minerals, Rocks and Products. J Mater Sci. 1978 Sept; 13(9): 1877-1886.

Hughes J, Callebaut K. Practical Sampling of Historic Mortars. In: Bartos, PJM, Groot, CJW, Hughes JJ, editors. Proceedings of the RILEM International Workshop, Historic Mortars: Characteristics and Tests. Paisley; 1999. p. 17-26.

Jose RT, Valenciano AM, Gregorio A, Parado-Cunanan $\mathrm{H}$, editors. Ilocos Norte: A Travel Guidebook. ${ }^{\text {st }}$ ed. Laoag City: Gameng Foundation, Inc. Museo Ilocos Norte; 2004. 
Lourenco PB, Fernandes FM, Castro F. Handmade Clay Bricks: Chemical, Physical and Mechanical Properties. Int J Architect Herit: Conserv Anal Restor. 2009; 4(1):38-58.

Lourenco PB, van Hees R, Fernandes F, Lubelli B. Characterization and Damage of Brick Masonry. In: Costa A, Guedes JM, Varum H, editors. Structural Rehabilitation of Old Buildings, Building Pathology and Rehabilitation, Volume 2. Berlin: SpringerVerlag; 2014. p. 109-130.

Mermut AR, Cano AF. Baseline Studies of the Clay Minerals Society Source Clays: Chemical Analysis of Major Elements. Clays Clay Miner. 2001; 49(5):381-386.

Navarro M, editor. Common Brick Manufacture. $1^{\text {st }}$ revised ed. Taguig City Metro Manila: Department of Science and Technology, Industrial Technology Development Institute; 2007 June.

Nwosu DC, Ejikeme PCN, Ejikeme Ebere M. Physio-Chemical Characterization of 'NGWO' White Clay for Industrial Use. Int J Multi Sci Eng. 2013 March; 4(3):11-14.

Osabor VN, Okafor PC, Ibe KA, Ayi AA. Characterization of Clays in Odukpani, South Eastern Nigeria. Afr J Pure Appl Chem. 2009 May; 3(5):079-085.

Punmia BC, Jain Ashok K, Jain Arun K. Comprehensive Basic Civil Engineering. Laxmi Publications; 2005.

Rai DC, Dhanapal S. Bricks and Mortars in Lucknow Monuments of c. 17-18 Century. Curr Sci. 2013 Jan; 104(2):238-244.

Sathya P, Velraj G, Meyvel S. Fourier Transform Infrared Spectroscopic Study of Ancient Brick Samples from Salavankuppam Region, Tamilnadu, India. Adv Appl Sci Res. 2012; 3(2):776-779.
Schroeder PA. Infrared Spectroscopy in Clay Science: In: Rule A, Guggenheim S, editors. CMS Workshop Lectures, Teaching Clay Science Volume 11. Aurora CO: The Clay Mineral Society; 2002. p. 181-206.

Senvaitiene J, Smirnova J, Beganskiene A, Kareiva. XRD and FTIR Characterisation of Lead Oxide-Based Pigments and Glazes. Acta Chim Slov. 2007; 54:185-193.

Sheikh MR, Barua AG. X-ray Diffraction and Fourier Transform Infrared Spectra of the Bricks of the Kamakhya Temple. Indian J Pure Ap Phy. 2013 Nov; 51:745-748.

Somayaji S. Civil Engineering Materials. $2^{\text {nd }}$ ed. New Jersey: Prentice-Hall, Inc.; 2001

Sposito G, Skipper NT, Sutton R, Park S, Soper AK, Greathouse JA. Surface Geochemistry of the Clay Minerals. Proc Natl Acad Sci. USA. 1999 March; 96:3358-3364.

Torraca G. Porous Materials Building: Material Science Architectural Conservation. $3^{\text {rd }}$ ed. ICCROM; 1988.

Uda M, Sassa S, Yoshimura S, Kondo J, Nakamura M, Ban Y, Adachi H. Yellow, Red and Blue Pigments from Ancient Egyptian Palace Painted Walls. Nucl Instrum Meth B. 2000; 161-163;758-761.

Velda B. Introduction to Clay Minerals: Chemistry, Origins, Uses and Environmental Significance. Springer Netherlands; 1992.

Zialcita F, Cruz-Angeles RB, editors. Balangkas: A Resource Book on the Care of Built Heritage in the Philippines. Philippine National Commission for Culture and the Arts (NCCA) Manila; 2007. 